\title{
DEPENDENCE OF TRACTOR INACTIVITY WORKING TIME ON FIELD SIZE DURING TILLAGE
}

\author{
Algirdas Janulevicius ${ }^{1}$, Vidas Damanauskas ${ }^{2}$ \\ ${ }^{1}$ Vytautas Magnus University, Lithuania; \\ ${ }^{2}$ Lithuanian Research Centre for Agriculture and Forestry, Lithuania \\ algirdas.janulevicius@vdu.lt, vidas.damanauskas@lammc.lt
}

\begin{abstract}
The main problems in the operation of agricultural tractors today are related to fuel consumption, work efficiency and environmental impact. The use of the engine power is one of the most important factors in evaluating the performance of a tractor in various tillage operations. Other characteristics of the tractor, such as the fuel consumption, work efficiency and also the impact on the environment, depend on this factor. The continuous tillage process can be divided into productive work operations and non-productive (non-working) operations. Nonworking operations include turns of the tractor at the headlands, also forced stops in order to eliminate machine malfunctions. When the tractor with the working unit turns in the headlands, the engine is running at the nearly idling mode. Idling mode is when the engine is completely unloaded and the tractor working unit is stationary. Idling is a common mode of operation of agricultural tractors, reducing the work efficiency and harming the environment and human health. In fact, agricultural tractors can idle from 10 to $45 \%$ of their entire working time. The aim of this work was to examine the methodology for estimating the duration of non-working operations in the tractor's long-term operation for ploughing fields of different size, based on the tractor's engine control units ECU data. This methodology should relate the duration of non-working operations of the tractor's operation with parameters describing the size and shape of the field. The results of this study can be used to develop a technological solution for agricultural work that reduces the inactivity working time of agricultural tractors.
\end{abstract}

Keywords: tractor, non-working operation, electronic controls, tillage, fuel consumption.

\section{Introduction}

Tractors are the main agricultural traction machines; they play a very big and important role in agriculture as they are the main source of mobile energy when working with various implements and agricultural machinery. The main problems in the operation of agricultural tractors today are related to fuel consumption, work efficiency and environmental impact [1;2]. Many sources of information show significant fuel savings by reducing the engine speed to $70-80 \%$ of rated speed and at maximum load, i.e., at least $80-85 \%$ of the maximum tractor power $[1 ; 3 ; 4]$. Irrational use of engine speed and power is a common status for agricultural tractors, reducing the efficiency and harming the environment [5].

The tillage process, like other tractor farm work, can be divided into productive work operations and non-productive (non-working) operations. Non- productive operations include turns of the tractor at the headlands, also forced stops in order to eliminate machine malfunctions. Non-productive operations include turns of the tractor at the headlands, also forced stops in order to eliminate machine malfunctions, as well as untargeted idling. Idling is the condition in which the engine is not under any load and the tractor is stationary. The tractor engine must be idling only under certain conditions (e.g., coupling the machine), otherwise it is a condition which consumes fuel and has a detrimental effect on the environment. According to various sources, agricultural tractors can idle from 10 to $43 \%$ of their total operating time [6; 7]. When the tractor with the working unit turns in the headlands, the engine is running at the nearly idling mode. Today, there are also major problems in determining and evaluating the performance of agricultural tractors [8].

A measure of tractor- machine unit performance during tillage and other field operations is its field efficiency, which is defined (ASAE, 2005) as the ratio between the productive work operations of the tractor-implement unit under field conditions and the theoretical maximum productivity $[9 ; 10]$. The field performance and efficiency of the tractor-implement is not constant, but it varies depending on the performance of the tractor-machine, the size and shape of the field, the terrain and soil structure, the operating mode model, pattern of manoeuvres in headland, and other conditions [11]. Today, there are still major problems in determining and evaluating the performance of agricultural tractors, especially when different field size and shape, terrain and soil structure, operating mode model, and so on. The use of real data for agricultural tractors is a relatively new topic, so it is necessary to identify the tractor inefficiencies. 
The aim of this work is to test the method of using the engine control data, which would allow to evaluate the performance of agricultural tractors in tillage (plowing) work in fields of different sizes.

\section{Materials and methods}

A tillage combination consisting of a Massey Ferguson MF6499 tractor and a Kverneland EG 100 reversible plough was used for the research. More or less similar fields of light loam wheat stubble of the same structure were selected for the study, in which the soil moisture at the depth of $10 \mathrm{~cm}$ reached $18.9 \pm 0.5 \%$, the soil hardness $-1.10 \pm 0.31 \mathrm{MPa}$. Four fields with ploughing zone lengths of 1000,750 , 500 and $250 \mathrm{~m}$, respectively, were prepared for the experiments. At the field ends, a manoeuvring scheme was used to turn the tractor, including the bow and reverse (T turn) [12]. When the tractor rotates in the headlands, the plough is turned over. During all field tests, the average theoretical ploughing speed of the tractor was about $2.63 \mathrm{~m} \mathrm{~s}^{-1}$ and the slip of the drive wheels varied between 8 and $12 \%$. This tractor speed was obtained with $1 \mathrm{~d}$ gear engaged at an engine speed of about $1800 \mathrm{rpm}$. One hour was allocated to each experiment in each field. Three replicates of the test were performed in each field.

The continuous tillage process consists of productive work operations and non-productive (nonworking) operations. Duration of productive work operations and non-working operations was calculated using load profile histograms. Massey Ferguson tractors are equipped with an electronic engine management system (EEM 3). The main functions of the EEM 3 are continuous (over time) measurement of the engine speed, torque and fuel supply and continuous recording of the engine operating time according to the engine speed and cyclic fuel injection quantity. A window is displayed showing the histograms of the engine load profile in revolutions per minute (rpm), fuel consumption (mg) and time (s) (Fig. 1).

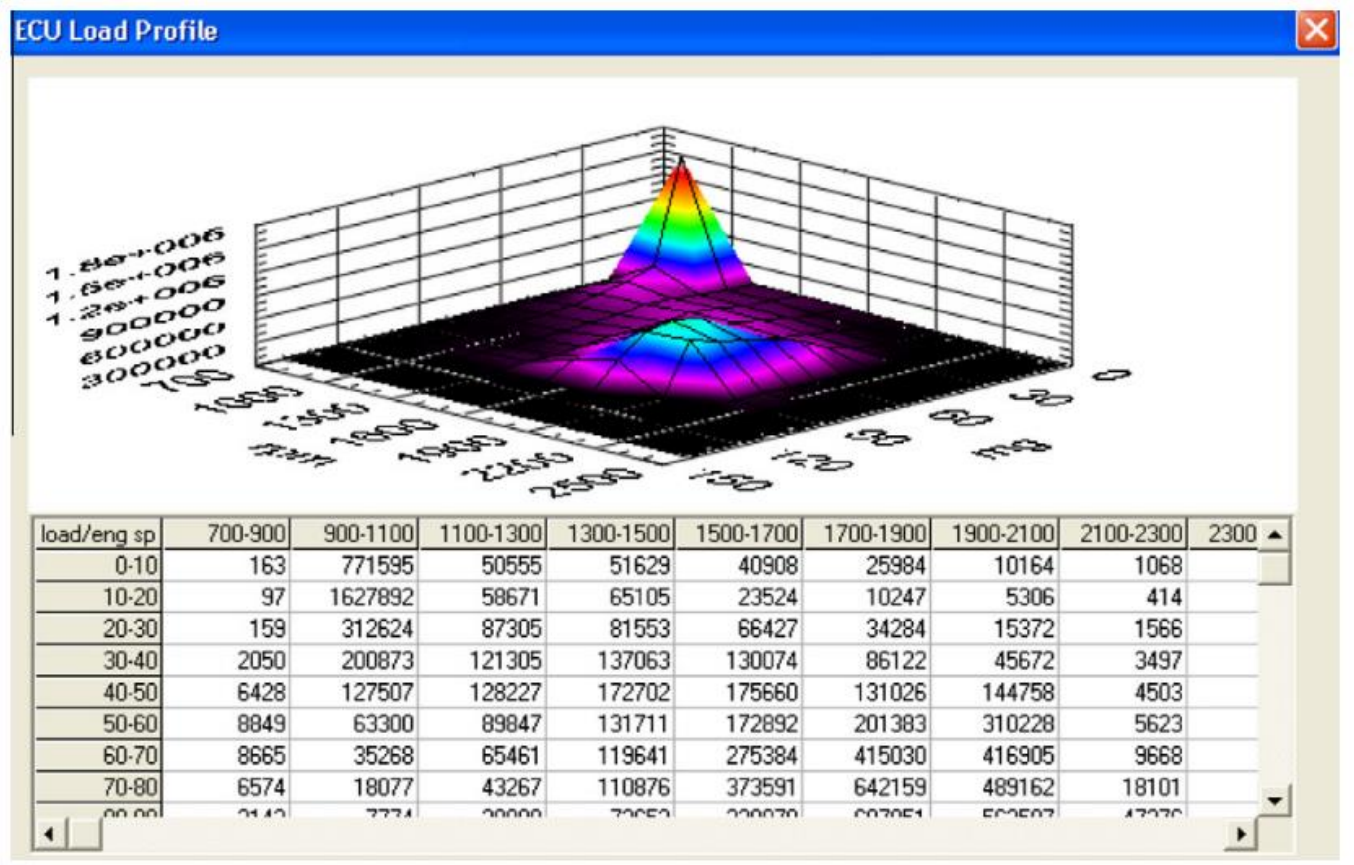

Fig. 1. "ECU Load Profile" histogram of tractors MF 6499 (sample)

The load profile histograms for the tillage test periods were obtained from the ECU load profile histogram recorded at the end of the tillage test, minus the ECU load profile histogram recorded before that test. The obtained engine load histograms show the engine modes for productive ploughing and idle work (non-working operations). This method of using an engine load profile histogram has been used in previous studies $[10 ; 13]$. Based on the histograms of the tillage test load profile, the total duration of the ploughing test, as well as the duration of productive and non-productive operation, can be calculated according to the following equations:

$$
t_{\Sigma}=t_{P}+t_{N}=\sum_{1}^{n} t_{m P}+\sum_{1}^{n} t_{m N},
$$

where $t_{\Sigma}-$ total duration of the ploughing test, $\mathrm{s}$; 
$t_{P}$ - duration of a productive ploughing operation, s;

$t_{N}-$ duration of non-productive operations, s;

$t_{m, P}$ - engine operating time at engine speed - cycle fuel injection modes to productive ploughing operations, $\mathrm{s}$;

$t_{m, N}$ - engine operating time at engine speed - cycle fuel injection modes non-working operations, units.

The efficiency of an agricultural tractor during field operations is its efficiency, which is defined in the ASAE, 2006 [14] as the ratio of production operation to the field time. According to ASAE standards (ASAE, 2005) [9], field time is the time an agricultural tractor spends in the field, measured continuously from the start of work to the end of field work.

In the following analysis, time efficiency coefficients expressed as the ratio of the duration of a productive ploughing operation to the total ploughing time were used to describe the fields of lengths:

$$
q=t_{P} / t_{\Sigma},
$$

where $q$-time efficiency coefficient;

$t_{P}-$ total duration of the ploughing test, $\mathrm{s}$;

$t_{\Sigma}-$ total duration of the ploughing test, s.

The total duration of the ploughing test $t_{\Sigma}$ and the duration of productive operations $t_{P}$ were determined from the tractor load profile histograms generated during the field tests.

The total fuel consumption during ploughing, including productive ploughing and non-working operations, was also calculated from the load profile histograms according to this equation:

$$
F_{\Sigma}=\sum_{m=1}^{m=n} 30 \cdot 10^{-6} n_{m} b_{m} e_{c} t_{m},
$$

where $F_{\Sigma^{-}}$total fuel consumption, $\mathrm{kg} \mathrm{h}^{-1}$;

$n_{m}$ - engine speed, min $^{-1}$

$b_{m}$ - cyclic fuel injection, mg cycle ${ }^{-1}$;

$t_{m}$ - engine operational time during engine speed-cyclic fuel injection modes, $\mathrm{h}$;

$e_{c}-$ number of the engine cylinders, units.

The tractor productivity $P$ (ha h-1) was calculated according to this equation:

$$
P=\frac{10^{-4} l W}{(l / 3600 v)+t_{h(1)}},
$$

where $l$-ploughed field length, $\mathrm{m}$;

$W$ - plough working width, m;

$v$ - travelling speed while ploughing, $\mathrm{m} \mathrm{s}^{-1}$;

$t_{h(1)}$ - time of one turn in the headland, $s$.

The average time of one turn in the headland was calculated using the following formula:

$$
t_{h(1)}=\frac{l}{3600 v}\left(\frac{t_{\Sigma}}{t_{P}}-1\right),
$$

The experiments and the presented calculations were performed for fields with a ploughing zone length of $1000,750,500$ and $250 \mathrm{~m}$, respectively.

\section{Results and discussion}

The distribution of the ploughing time of one hour, 1000, 750, 500 and $250 \mathrm{~m}$ in the length fields according to the engine speed-cyclic fuel injection modes is shown in Figure 2

The graphs in Figure 2 clearly show the two most time-consuming groups of engine operating modes: ploughing and idling when the tractor is turning in the headland. Between these two modes are the transient engine operating modes that occur when the plough is lowering or raising. In addition, Figure 2 shows that in the shortest field it took significantly more time to turn at the headlands, although the individual turns of the tractor took about the same amount of time, averaging about $63 \mathrm{~s}$. 

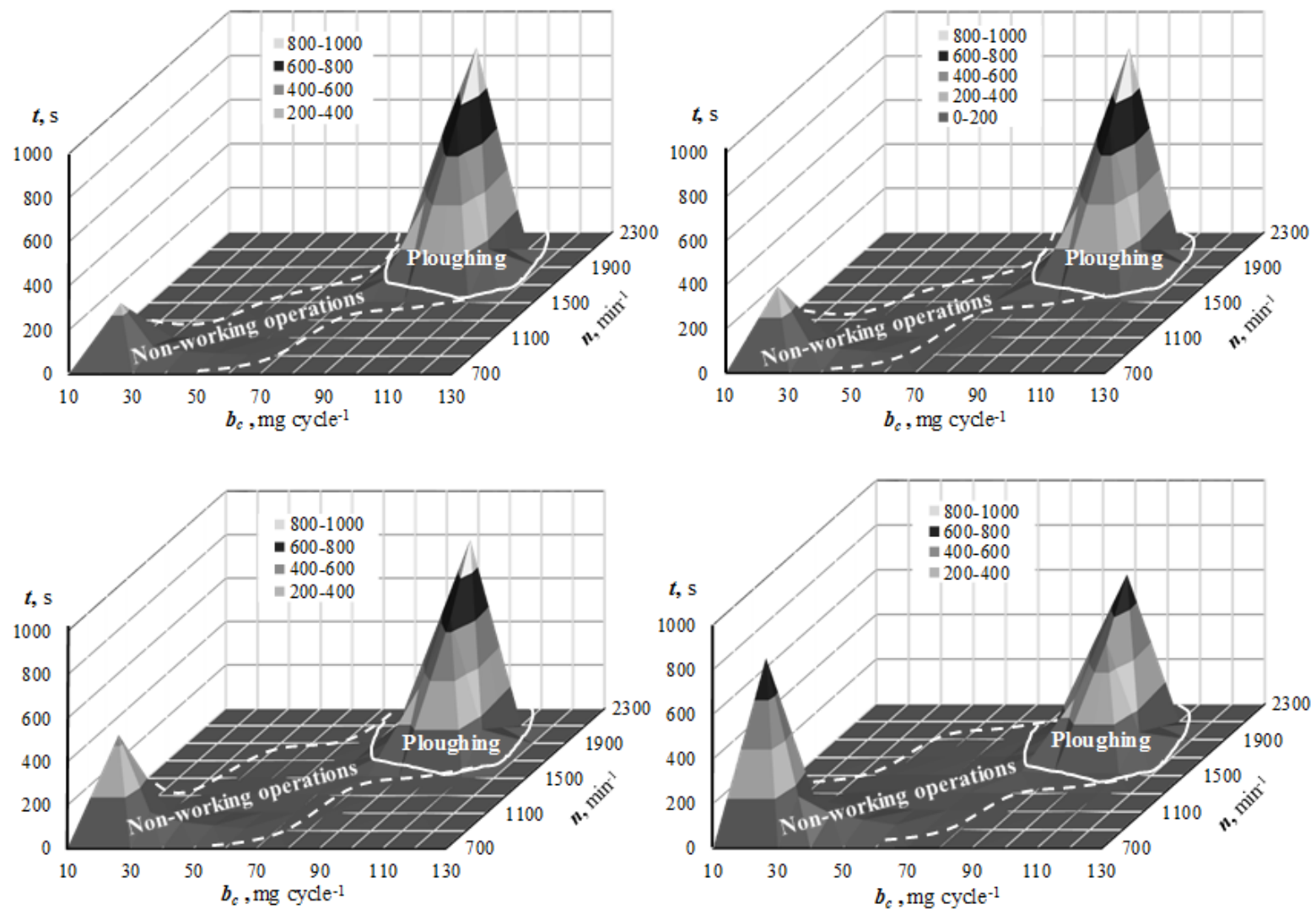

Fig. 2. Distribution of one-hour ploughing time in 1000, 750, 500 and $250 \mathrm{~m}$ fields according to engine speed and fuel injection modes

From the histograms in Figure 2, the values of the tractor operation time efficiency factors were determined, which are expressed as the ratio of the duration of the productive ploughing operation to the total ploughing time. When ploughing fields of 1000, 750, 500, and $250 \mathrm{~m}$ in length, the values of the time efficiency coefficient q were determined to be $0.879,0.843,0.778$, and 0.614 , respectively. The dependence of the distribution of one-hour ploughing time between the ploughing operation time $t_{P}$ and non-working time $t_{N}$ on the time efficiency factor $q$ is shown in Figure 3.

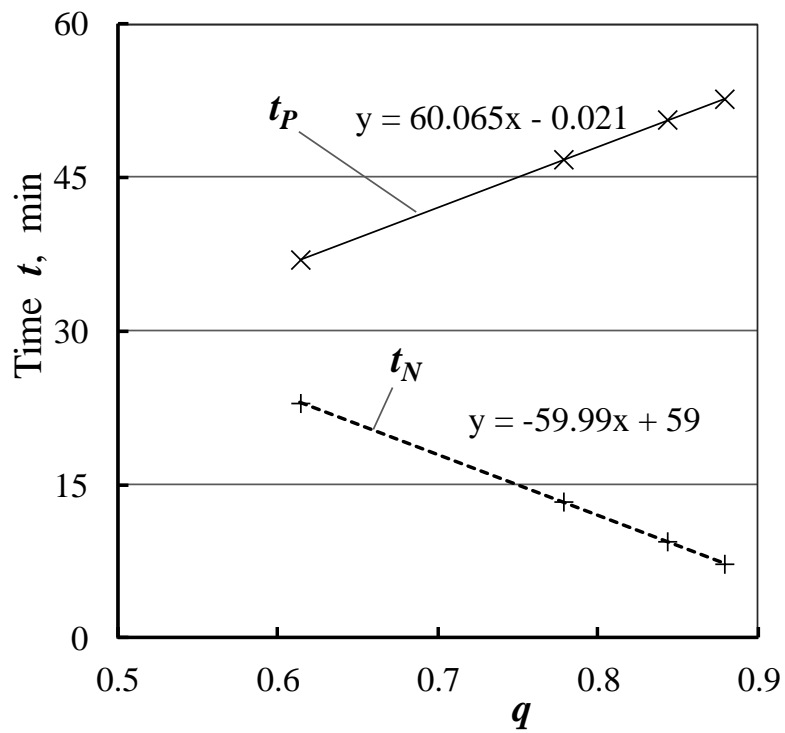

Fig. 3. Dependence of distribution of one-hour ploughing time between the ploughing operation time $t_{P}$ and non-working time $t_{N}$ on the time efficiency factor $q$ 
The obtained results show that the distribution of the total ploughing time between the ploughing operation time and non-working time according to the time efficiency coefficient is based on a linear model. With the time efficiency factor of 0.75 , the time of productive ploughing operations was about $75 \%$ and the inactivity time was about $25 \%$. The graph shows that as the time efficiency factor $q$ increases by 0.1 , the duration of the ploughing operation $t_{P}$ increases by about $6.01 \mathrm{~min}$, and the nonworking time $t_{N}$ decreases by $6.01 \mathrm{~min}$. Figure 4 shows the dependences of tractor productivity and fuel consumption on the time efficiency factor obtained from the Massey Ferguson MF6499 tractor test data during ploughing application with the field length equal to $1000,750,500$ and $250 \mathrm{~m}$.
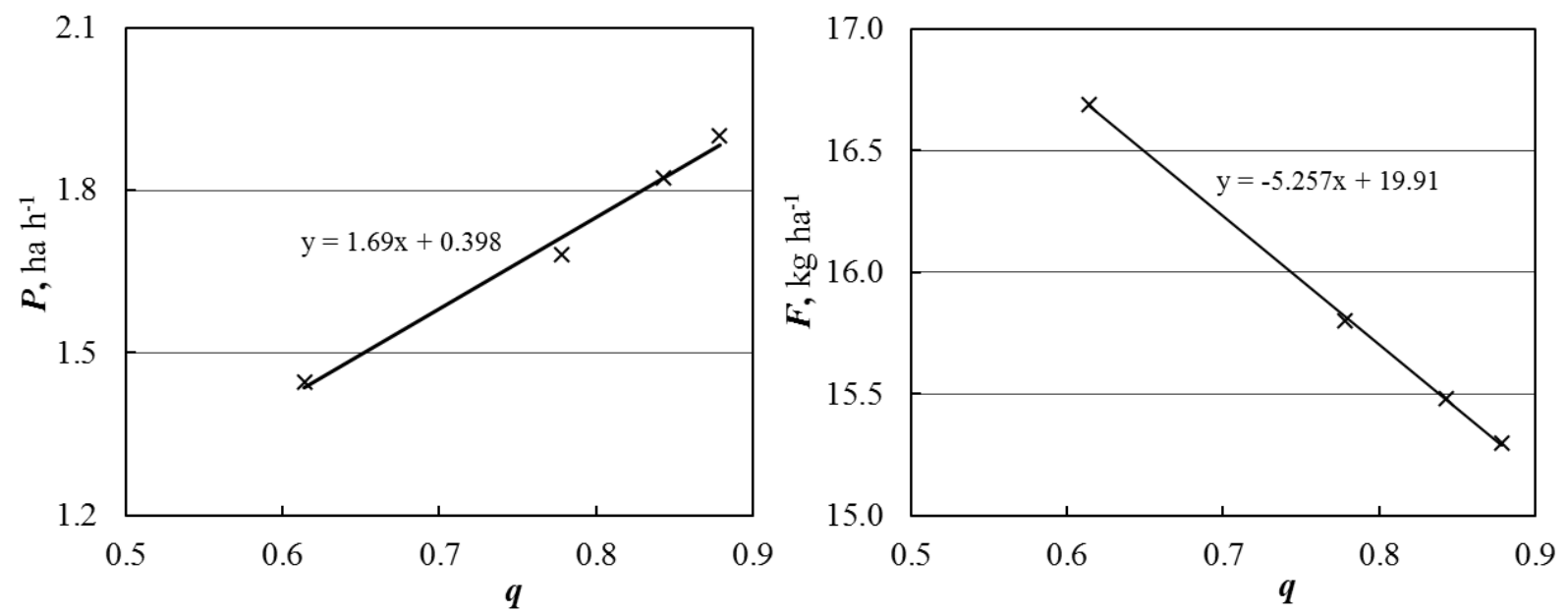

\section{Fig. 4. Dependence of tractor productivity $\boldsymbol{P}$ and fuel consumption $\boldsymbol{F}$ on time efficiency factor $q$}

The obtained results show that the dependence of the tractor productivity and fuel consumption on the time efficiency varies according to the linear dependence. With an increase in the time efficiency of about 0.1 , the tractor productivity increased by about $14.3 \%$ and the fuel consumption decreased by about $3.45 \%$.

\section{Conclusions}

1. To describe the performance of the tractor in fields of different sizes, the time efficiency factor can be calculated using the engine load profile histograms rewritten from the electronic engine control system.

2. It was found that the distribution of the total ploughing time between the ploughing operation time and non-working time according to the time efficiency coefficient is based on a linear model. When ploughing fields of 1000, 750, 500 and $250 \mathrm{~m}$ in length, when the time efficiency factor increases by about 0.1 , the duration of the productive ploughing operation increases by about $10 \%$ and the non-productive time decreases by $10 \%$.

3. The dependence of the tractor productivity and fuel consumption on the time efficiency was found to be linear. When ploughing fields of $1000,750,500$ and $250 \mathrm{~m}$ in length, with an increase in the time efficiency of about 0.1 , the tractor productivity increased by about $14.3 \%$ and the fuel consumption decreased by about $3.45 \%$.

\section{References}

[1] Karparvarfard S.H., Rahmanian-Koushkaki H. Development of a fuel consumption equation: Test case for a tractor chisel-ploughing in a clay loam soil. Biosystems engineering, 130, 2015, pp. 23 33.

[2] Lee J.W., Kim J.S., Kim K.U. Computer simulations to maximise fuel efficiency and work performance of agricultural tractors in rotovating and ploughing operations. Biosystems engineering, 142, 2016, pp. 1-11.

[3] Pitla S.K., Luck J.D., Werner J., Lin N., Shearer S.A. In-field fuel use and load states of agricultural field machinery. Computers and Electronics in Agriculture, 121, 2016, pp. 290-300. 
[4] Čiplienė A., Gurevičius P., Janulevičius A., Damanauskas V. Experimental validation of tire inflation pressure model to reduce fuel consumption during soil tillage. Biosystems Engineering, 186, 2019. pp. 45-59.

[5] Bacenetti J., Lovarelli D., Facchinetti D. An environmental comparison of techniques to reduce pollutants emissions related to agricultural tractors. Biosystems engineering, 171, 2018, pp. 30-40.

[6] Molari G, Mattetti M, Lenzini N, Fiorati S. An updated methodology to analyse the idling of agricultural tractors. Biosystems engineering, 187, 2019, pp. 160-170.

[7] Lovarelli D., Fiala M., Larsson,G. Fuel consumption and exhaust emissions during on-field tractor activity: A possible improving strategy for the environmental load of agricultural mechanisation. Computers and Electronics in Agriculture, 151, 2018, pp.238-248.

[8] Perozzi D., Mattetti M., Molari G., Sereni E. Methodology to analyse farm tractor idling time. Biosystems engineering, 148, 2016, pp .81-89.

[9] ASAE standards, 2005. S495 uniform terminology for agricultural machinery management. St. Joseph, Michigan: ASABE.

[10] Janulevičius A., Šarauskis E., Čiplienė A., Juostas A. Estimation of farm tractor performance as a function of time efficiency during ploughing in fields of different sizes. Biosystems Engineering, 179, 2019, pp.80-93.

[11] Plessen M.G. Optimal in-field routing for full and partial field coverage with arbitrary non-convex fields and multiple obstacle areas. Biosystems engineering, 186, 2019, pp. 234-245.

[12] Bochtis D.D., Vougioukas S.G. Minimising the non-working distance travelled by machines operating in a headland field pattern. Biosystems engineering, 101, 2008, pp. 1-12.

[13] Janulevičius A., Čiplienè A. Estimation of engine $\mathrm{CO}_{2}$ and $\mathrm{NO}_{x}$ emissions and their correlation with the not-to-exceed zone for a tractor ploughing fields of various sizes. Journal of Cleaner Production, 198, 2018, pp. 1583-1592.

[14] ASAE standards, 2006. EP496.3 agricultural machinery management. St. Joseph, Michigan: ASABE. 